Revista Iberoamericana. Vol. LXIV, Núms. 184-185, Julio-Diciembre 1998; 381-396

\title{
EL 98 CUBANO Y LA HERENCIA DE UNA VISIÓN ROMÁNTICA
}

\author{
POR \\ Aída M. BEAupied \\ The Pennsylvania State University
}

En tanto que para los españoles el 98 se cargó rápidamente de significado, sirviendo de inspiración a las reflexiones de alto calibre que hoy día conocemos como los frutos de toda una generación de pensadores y literatos, en Cuba ha sido mucho más lento y difícil el proceso de consolidar una idea fija - suficientemente diseminada como para hacerla parecer irrebatible-sobre las repercusiones de ese momento tan señalado en su historia. Manuel Moreno Fraginals advierte que aunque en España y en los Estados Unidos el 98 recibió una definición concisa e inmediata - “derrota" para España, "victoria" para los Estados Unidos - en Cuba no ocurrió así: "Para Cuba aún no se ha hallado la definición exacta: como en los versos de Lezama Lima, Cuba [la del 98] parece escaparse cuando uno cree haber hallado la definición mejor" (293). Añade Moreno Fraginals que en la Cuba a partir de 1959 sí se ha encontrado una definición del 98, "como el año en que Cuba dejó de ser colonia de España para serlo de los Estados Unidos" (293); sin embargo, Fraginals aclara que esto no es cierto ya que, en términos económicos, "desde mediados del siglo diecinueve Cuba había ido lenta pero inexorablemente pasando a ser un país dependiente de los Estados Unidos" (293).

La versión oficial de la historia de Cuba a partir de 1959 dramatiza el 98 como un momento culminante en que se repite la victimización del pueblo cubano a manos de otra metrópolis colonial, en este caso los Estados Unidos. Por ejemplo, según Francisco Pérez Guzmán: "El proceso revolucionario cubano, iniciado en 1868, fue cortado en su desarrollo por la intervención norteamericana que escamoteó la victoria de las fuerzas libertadoras populares" (541). Sin embargo, la culpa de ese fracaso no fue exclusiva de los Estados Unidos y tuvo mucho que ver con la fragmentación entre los propios cubanos de dentro y fuera de la isla. Esa fragmentación se hizo más visible en los tres grupos que buscaban una solución a los problemas del país: anexionistas, autonomistas e independentistas. Menos visibles han sido las divisiones internas entre estos grupos, sobre todo las de los independentistas. Los que lucharon en la primera guerra de independencia - la guerra de Yara o del 68 - estaban divididos por razones económicas y políticas y el debilitamiento causado por esa fragmentación fue un obstáculo significativo en el desarrollo de esa guerra. Las divisiones entre los independentistas de la guerra del 95 eran aún más profundas y desembocaron en lo que, en fechas más recientes, se ha descrito como una lucha de clases. Por ejemplo, Pérez Guzmán explica que entre los independentistas cubanos había dos 
grupos antagónicos: por un lado estaban "los sectores antinacionales de la burguesía y sus acólitos", quienes llegado el momento, se aliaron a los Estados Unidos a fin de proteger sus intereses; por el otro lado estaban las fuerzas cuyo objetivo era obtener la independencia nacional, para de esa manera lograr el "mejoramiento de las condiciones sociales de los sectores populares" (541). También Louis A. Pérez se adhiere a esa visión de la guerra como una lucha de clases: "The war was now against the dominant social class, the local collaborators of colonialism: a war waged against the beneficiaries of colonialism by the victims of colonialism" (162). Lo cierto es que, una buena manera de describir el siglo diecinueve cubano es llamando la atención hacia las divisiones que poco a poco fueron minando los ideales de independencia. ${ }^{1}$

No hay duda que hay mucha más derrota que victoria en ese año en el que se registra una destrucción tan vasta que afectó todas las esferas del país, un año que, además, marca la primera ocupación militar por parte del país vecino que se aprovechó del debilitamiento por el que atravesaba la isla para expandir sus intereses y asegurar en ella su control. Un rasgo común entre los historiadores de dentro y fuera de Cuba a la hora de narrar la independencia fallida, postergada, y en muchos sentidos robada por los Estados Unidos en 1898, ha sido el deseo de encontrar las causas de este fenómeno. Los culpables más señalados suelen ser España, los Estados Unidos, los cubanos traidores, los cubanos pasivos que no contribuyeron a la causa, la burguesía cómplice de los intereses colonialistas. Este ensayo propone añadir otro culpable a la lista: la culpa misma, sobre todo la que fragmenta al sujeto y lo lleva a proyectar esa fragmentación en agentes externos. A la hora de considerar esa culpa se hará necesario tomar en cuenta de qué manera su papel en el drama que fue el siglo diecinueve cubano se inspiró en una visión de mundo heredada del romanticismo.

Es cosa sabida que el siglo diecinueve cubano - sobre todo en lo que respecta a los sentimientos patrióticos - se caracteriza por un fuerte legado del romanticismo. Sabemos también que el legado del romanticismo no sólo afecta a los letrados de la época sino que fue un movimiento popular cuya influencia tuvo gran repercución entre las masas. Recordemos además que el romanticismo poético de Cuba - tan importante en el pensamiento político del siglo diecinueve- coincide con ese abandono del decorum neoclásico en favor de una "poesía de crisis"; ${ }^{2}$ es decir, una poesía que dramatiza la separación, el exilio y, sobre todo, la irreconciliable lucha de contrarios. Y aunque es indudable que esa visión no se origina en el diecinueve, es válido asociarla con el romanticismo que la exaltó y diseminó en formas que todavía hoy siguen siendo su legado.

Hay además una "visión romántica" en la que participan los intérpretes de las luchas por la independencia de Cuba. Se trata de la visión maniquea que pretende dividir la historia entre víctimas y victimarios y que, aunque subsiste, hoy día ha sido ya muy debatida. Un ejemplo de desmitificación lo ofrece el libro de José M. Hernández, Cuba and the United

\footnotetext{
' Importa aclarar que, aunque la fragmentación hizo mella en los ideales independentistas, éstos no sólo no desaparecieron sino que su ímpetu hizo posible que Cuba adquiriese su independencia en 1902.

${ }^{2}$ Me inspiro aquí en los comentarios de Andrew Bush sobre la manera en que el romanticismo de Heredia sobrepasa a los poetas neoclásicos españoles (392).
} 
States. Intervention and Militarism, 1868-1933(1993), donde Hernández muestra cómo el militarismo de los primeros años de la Cuba republicana está íntimamente ligado a la toma del poder político de una generación de "héroes menores", veteranos de las guerras de independencia, quienes lograron establecerse como la nueva clase dominante con el respaldo de las intervenciones militares norteamericanas. Aunque el libro de Hernández responsabiliza parcialmente al gobierno de Estados Unidos por la corrupción gubernamental que se iba a hacer más y más señalada a partir de la década de los treinta, uno de sus aspectos más reveladores es la desmitificación de la lucha cubana por la autonomía nacional. Lejos de repetir las versiones "románticas" en que la ambición tiránica del colonialismo es el principal culpable de las desgracias de la Cuba republicana, el libro de Hernández muestra cómo entre los militares del ejército libertador, al igual que ocurrió en casi toda Hispanoamérica, germinaba la semilla de la ambición de poder y tiranía. Otro ejemplo lo ofrece el último libro de Manuel Moreno Fraginals, Cuba/España, España/Cuba. Historia común (1995). Como sugiere el título, en este libro Fraginals pone menos énfasis en las diferencias entre Cuba y España y llama la atención sobre la relación simbiótica que existió a lo largo de una historia compartida por ambos países.

Las lecturas de historiadores como Moreno Fraginals y Hernández son revisiones de lo que se puede describir - cubanizando el término de Lyotard- como el "gran novelón" de la historia de Cuba. $^{3}$ En cambio, posiblemente por estar todavía cerca del siglo diecinueve, un importante pensador como Medardo Vitier no pudo superar la visión "romántica" de la historia de la independencia en su libro de 1938, Las ideas en Cuba. En su esfuerzo por conciliar la sociología, la sicología, y el espiritualismo hegeliano que el materialismo histórico había intentado obliterar, Medardo Vitier explica lo que para él son los factores que entran a formar parte de la historia:

El medio, en todo su bullente contenido de intereses; la innovación o el suceso; y la individualidad del agente que, en algunos casos, es decisiva y rebasa por su influjo posterior, los fines a que se limitó. Es que al cabo, lo inmediato y urgente radica en lo material y cotidiano, pero lo infinito es el espíritu, por la fecundidad que lleva in potentia (111).

Uno de los objetivos de Vitier es trazar el itinerario de las ideas que llevaron a las guerras de independencia. Como lo delata la cita anterior, en su trayectoria Vitier le da un papel importante a la participación del individuo o agente del espíritu. De acuerdo a Vitier, esa individualidad va a ser doblemente importante en el siglo diecinueve ya que ésta fue una época plagada por las ideas de los derechos del individuo. ${ }^{4}$ Explica Vitier que esas ideas se vieron reflejadas en el altruismo de los líderes de las guerras de independencia cubana: "Lo básico, - y aceptemos que sea lo económico- suele desaparecer como factor

\footnotetext{
${ }^{3}$ Aludo a las "narrativas maestras" de que habla Lyotard (27-31).

4 "La cultura política de los cubanos preparados, en consecuencia, las aspiraciones y en último término la acción, - bélica, o de partido - todo se derivaba del ideario individualista en boga. El Derecho Natural que alimentó la doctrinas jurídicas durante los siglos XVII y XVIII, en Europa, cuajó triunfante en la Declaración de derechos francesa, transida de racionalismo y de individualismo" (Medardo Vitier 127).
} 
consciente, psicológico, porque cede lugar a los motivos ennoblecedores: al sentido de la justicia, a la noción de desigualdad humana, etc. Por manera que las fuerzas animadoras, una vez que la acción se despliega, no son los intereses materiales" (191). De acuerdo a esta visión, los éxitos y fracasos de los "agentes del espíritu" estaban directamente relacionados a los conflictos entre ideas e intereses que había en el ambiente de la época. Esto lleva a Vitier a concluir que los "motivos ennoblecedores" de los líderes de la independencia - y en particular Vitier alude aquí a la guerra del 68-muestran que el móvil económico no era el único que impulsaba a aquellos hombres y que el empeño libertador fracasó porque las ideas de las minorías no lograron diseminarse por la población (196).

Hoy día sabemos que a pesar de la considerable dosis de altruismo que había entre los líderes y soldados de las guerras de independencia de Cuba, ese altruismo estuvo contaminado por otros factores. Apenas cinco años después de la lectura que hiciera Medardo Vitier del diecinueve, Jorge Mañach continúa y revisa a Vitier en su tratamiento del mismo tópico. Como ya había hecho Vitier, Mañach le resta importancia a la lectura marxista que pone énfasis en los factores económicos que impulsaron las guerras de independencia y prefiere, también como Vitier, darle más importancia al espíritu. Sin embargo, el papel que Mañach le asigna al espíritu aparece contaminado:

Hoy ya se advierte y reconoce que no hay tal determinismo económico absoluto; que el factor económico es sólo uno, y probablemente el más imperioso, de los factores llamados "materiales" que condicionan la conducta humana; pero que, al margen de éstos, queda siempre una misteriosa zona de autodeterminación del espíritu, donde juegan su papel, tan dramático a veces para el propio individuo, los puros impulsos emocionales, los narcisismos, los pudores y los orgullos, las ambiciones netas de gloria o de poder y hasta los más oscuros y seculares atavismos (50-51).

Algo que tienen en común las lecturas de Vitier y Mañach es la presentación de un individuo cuya participación en la historia es superada por esa entidad que trasciende la historia misma: el espíritu. Hoy día a la participación del individuo en la historia se le concede aun menos relevancia ya que éste aparece como producto del proceso social que lo construye como agente más o menos capacitado para alterar la historia. Independientemente de sus virtudes como agente, una buena parte de los mecanismos que mueven los procesos en los que ese individuo participa se conciben fuera del alcance de su comprensión, lo cual le impide ejercer total control sobre sus acciones. Tal visión de la historia renuncia a todo reclamo de objetividad y, más importante todavía para los fines de este ensayo, renuncia a creer en esa lectura única que descifra, sin ambigüedades, cómo sus acciones llevan al ser humano al único e inevitable fin para el que estaba destinado. Por el contrario, la historia aparece como un texto abierto a interpretaciones diversas, siempre interesadas, siempre prejuiciadas, y con frecuencia contradictorias. Consciente de que la libertad que esta visión concede a la hora de interpretar un evento histórico encierra también muchos peligros, este ensayo propone una lectura del 98 cubano que ponga énfasis en la huella que el romanticismo ha dejado en sus páginas.

Una entre muchas maneras de reinventar especulaciones alrededor del 98 cubano la ofrece la literatura, y en específico el análisis de la poesía romántica de tema patriótico. Los eventos alrededor de ese año clave, incluyendo la intervención norteamericana en la guerra 
de Independencia y la consiguiente demora de lo que eventualmente llegaría a ser el acta de bautismo de la ciudadanía cubana - la puesta en marcha de la primera constitución de la República - invitan a ser leídos a la luz de una retórica y unas actitudes muy ligadas a nuestro, hasta ahora inagotable, romanticismo patriótico. Y aquí "romanticismo patriótico" no sólo alude a la retórica tan predominante todavía en los discursos de dentro y fuera de la isla, sino a esa manera típicamente alienada con que el sujeto romántico de la poesía del siglo diecinueve cubano describe su martirio y el de la patria esclava.

Claro que hay numerosos precedentes de esa temática en las obras del romanticismo europeo, obras éstas que los cubanos conocían bien. Es por eso que, sin perder de vista el hecho de que el romanticismo cubano le debe mucho a la imitación de modelos europeos, será bueno notar la coincidencia entre la percepción del sujeto alienado, y en muchos casos martirizado, y ese momento clave que fue el 98, cuando tanta profecía de fracaso, separación y culpas parece llegar a cumplirse. No se pretende aquí explicar cómo el complejo momento que fue el 98 se justifica en virtud de un legado del romanticismo, pero sí importa llamar la atención hacia los lazos estrechos que hay entre la percepción fragmentada, típica del sujeto romántico, y lo que en el 98 culmina como un fracaso en la adquisición de una identidad unificada; es decir, una identidad nacional capaz de regirse por el ideal martiano de una patria "con todos y para el bien de todos".

Aunque la alienación no es un padecimiento exclusivo del sujeto romántico, es en la filosofía y las artes de este período cuando con mayor empeño se llega a problematizar, y con frecuencia a glorificar, la condición alienada de un sujeto que lucha más o menos inútilmente para ponerle fin a su exilio existencial. Recordemos que gran parte del proyecto romántico consiste en confrontar una separación que se hace más insalvable a medida que se agranda el abismo dejado por "la muerte de Dios". Recordemos también que se trata de una separación asociada al pecado original, es decir, a la culpa mítica. Las versiones de la separación son incontables: sujeto/mundo, hombre/Dios, vida/muerte, ideal/realidad, lo nombrado/el lenguaje. Sin embargo, la culpa tiene apenas dos variantes, disímiles sólo en apariencia: la que se proyecta en un agente externo y la que se manifiesta como autocrítica. $\mathrm{Y}$ es que, desde la invención de la fruta prohibida, la culpa ha estado relacionada a la desnudez, a la vergüenza que viene con el reconocimiento de la desnudez, es decir, a la autocrítica. Antonio Benítez-Rojo ha registrado una de las primeras manifestaciones literarias de la culpa en el Nuevo Mundo, según ésta aparece en los escritos de Fray Bartolomé de las Casas, en sus defensas de los indios de quienes él mismo fuera una vez encomendero (70). Ya cuando llegamos al crítico siglo diecinueve encontramos el discurso de la culpa en la voz de uno de sus más destacados e influyentes pensadores, José de la Luz y Caballero, quien hace el siguiente comentario sobre la esclavitud: "La introducción de los negros en Cuba es nuestro verdadero pecado original, tanto más cuanto que pagarán justos por pecadores" (82).

El comentario de Luz y Caballero ejemplifica lo que para Medardo Vitier fue el "período crítico" que ya hacia fines del dieciocho, a raíz de los esfuerzos de José Agustín Caballero y más tarde del padre Varela, va a predominar a lo largo del siglo diecinueve (143). Según Medardo Vitier, hay épocas orgánicas, donde predominan el equilibrio y una paz relativa que permiten el crecimiento y la construcción, y épocas críticas que "remueven, abaten, cancelan" (12). La labor de los pensadores críticos tuvo el efecto de substituir el 
curriculum medieval, imperante en los sistemas de enseñanza cubanos, por las ideas del cartesianismo y la ciencia moderna. No hay duda que los cambios propiciados en el sistema de enseñanza representaron una renovación indispensable en el desarrollo de la cultura; sin embargo, inevitablemente ligada a ese espíritu crítico está la semilla de la contradicción. Y esa contradicción va a ser responsable no sólo de grandes aporías en el pensamiento de toda una era, sino que se verá reflejada en ese impasse histórico que fue el 98.

Sabemos que los maestros, poetas y ensayistas del diecinueve divergían en sus aspiraciones a la hora de solucionar el problema de Cuba y que estaban fragmentados en los tres grupos que dividían el pensamiento político. Es cierto que esa fragmentación no siempre era insalvable ni estricta, que todos compartían el deseo de ponerle fin al insostenible sometimiento a España, y que a todos les impulsaba el deseo de alcanzar una unidad; esto es, una unión de criterios y esfuerzos suficientemente fuerte como para llevar a cabo sus aspiraciones, las que - en el caso de los independentistas - habrían de desembocar en ese perfecto emblema de unidad que iba a ser la República. Sin embargo, el deseo de llegar al consenso no era compatible con el vehículo del que mayormente se sirvieron, tanto en prosa como en poesía, para tratar de alcanzar la unidad de criterio: la crítica, y en particular la crítica que, para causar mayor impacto, adorna su discurso de culpas, miedo y rencor.

Hoy día sabemos que la crítica es el agente de la separación por excelencia y que su objetivo es juzgar y luego dividir en categorías antagónicas. Independientemente de si el impulso crítico que se origina en una división interna se proyecta al exterior o desemboca en autocrítica, lo cierto es que tanto la crítica que se proyecta como la que se internaliza van siempre de la mano. Veamos esa confluencia en el discurso de inauguración de la cátedra de Filosofía del Seminario de San Carlos, en 1824, en el que Luz y Caballero hace el siguiente comentario a propósito de Descartes: "[...] él [Descartes] nos aconseja que empecemos dudando de todo, haciéndonos cargo de que nada sabemos [...] La duda produce una desconfianza en nosotros mismos que nos despoja de toda presunción [...]" (25). En este discurso de apertura que ofrece el maestro de maestros del pensamiento cubano decimonónico, tenemos un aviso de lo que puede sobrevenir cuando se aplica la duda sistemática: "la desconfianza en nosotros mismos", es decir, la separación o distancia crítica del yo consigo mismo y con lo que le rodea.

Esa desconfianza, sin ser ella misma salvavidas de redención, resulta muy productiva cuando la labor crítica no ceja, cuando incluso las verdades más sagradas pueden ser puestas en tela de juicio. Pero ese no fue el caso de los pensadores críticos del diecinueve, para quienes el territorio sagrado de la religión se reformula a fin de adaptarse a la retórica romántica de la victimización del yo. Es así que, para José de la Luz y Caballero, la desventura se asocia al Bien: "Bienaventurados los males, y más bienaventurada la religión sacrosanta, que nos arrancáis de este lodo terrenal y nos eleváis hasta el cielo" (53). La glorificación del sufrimiento está muy ligada en esta época a la literatura y en particular a la figura del poeta romántico. El propio Luz y Caballero se suscribe a una muy en boga visión del poeta, cuyo sufrimiento glorifica al asociarlo a la labor del genio: "La desventura, el alimento y aun germen del genio. Todos los poetas inmortales fueron tan célebres por sus desdichas como por sus obras [...]" (77-78). Esa glorificación del sufrimiento, tan cotizada y diseminada a lo largo de la historia del cristianismo, le permite a Luz y Caballero 
establecer semejanzas entre dos términos antagónicos, el amor y el temor: "Quien no teme no ama" (89). Lo que sugiere este aforismo es que el temor es requisito para que haya amor. Veamos la incongruencia de esta "lógica". La existencia del amor - palabra que un católico como Luz y Caballero asocia al Bien y, por lo mismo, a la ausencia de todo mal, incluyendo el temor-depende de su coexistencia con el temor. Es posible que muchos lectores de este ensayo no vean discrepancias en la unión de estos términos pero, ¿acaso esta inclinación nuestra a mezclar, confundir lo incompatible no es otro legado que, si bien el romanticismo no inventó, sin duda se encargó de propagar? Es común que en una sola persona se den cita al mismo tiempo dos sentimientos contrarios, pero esa coexistencia es insuficiente para establecer semejanzas entre lo incompatible. Veamos ahora cómo el hábito, tan popular durante el romanticismo, de confundir sentimientos incompatibles fue un ingrediente esencial en los escritos que ayudaron a forjar la identidad nacional cubana.

La interacción de José Martí con los dos principales líderes de la independencia de Cuba, Máximo Gómez y Antonio Maceo, ofrece un ejemplo de esa confluencia de sentimientos opuestos, que unas veces se reprimen y otras se disfrazan. En octubre de 1884 Martí tuvo una reunión con ambos generales y, como él mismo cuenta en una carta dirigida a Gómez, la reunión le hizo ver que la libertad de Cuba estaba amenazada por el espíritu déspota que Martí adivinaba en Gómez y Maceo:

Salí en la mañana del sábado de la casa de Vd. con una impresión tan penosa, que he querido dejarla reposar dos días, para que la resolución que ella, unida a otras anteriores, me inspirase, no fuera resultado de una ofuscación pasajera, o excesivo celo en la defensa de cosas que no quisiera ver yo jamás atacadas, - sino obra de meditación madura: —iqué pena me da tener que decir estas cosas a un hombre a quien creo sincero y bueno, y en quien existen cualidades notables para llegar a ser verdaderamente grande! -Pero hay algo que está por encima de toda simpatía personal que $\mathrm{Vd}$. pueda inspirarme y hasta de toda razón de oportunidad aparente: y es mi determinación de no contribuir en un ápice, por amor ciego a una idea en que me está yendo la vida, a traer a mi tierra a un régimen de despotismo personal, que sería más vergonzoso y funesto que el despotismo político que ahora soporta, y más grave y difícil de desarraigar, porque vendría excusado por algunas virtudes, embellecido por la idea encarnada en él, y legitimado por el triunfo.

Un pueblo no se funda, General,como se manda un campamento [...] ¿Qué somos, General?: ¿los servidores heroicos y modestos de una idea que nos calienta el corazón, los amigos leales de un pueblo en desventura, o los caudillos valientes y afortunados que con el látigo en la mano y la espuela en el tacón se disponen a llevar la guerra a un pueblo, para enseñorearse después de él? (Obras Completas I, 177-178).

Resistiendo en lo posible la tentación de apasionarnos ante los poderosos razonamientos de Martí, tan relevantes hoy día, analicemos cuáles fueron las consecuencias de esta carta, en el marco de las labores de Martí a favor de la independencia y de sus relaciones con los futuros líderes de la guerra del 95. La historia nos dice que una consecuencia inmediata de la carta fue un enfriamiento en las relaciones entre Martí y los generales. Cuando volvieron a tratarse lo hicieron por conveniencias mutuas; es decir, los generales necesitaban el apoyo financiero y político del Partido Revolucionario Cubano, fundado y dirigido por Martí, y éste necesitaba de los estrategas militares para llevar a cabo la guerra. Sin embargo, la muralla entre ellos ya había quedado alzada con esa carta y ella explica mucha de la 
resistencia que encontró Martí en el trato con ambos generales, sobre todo con Maceo. Una consecuencia a largo plazo la vemos en el trato que Maceo y Gómez tuvieron para con Martí en 1895, cuando ya en plena guerra Martí casi estuvo a punto de ser enviado de vuelta a Nueva York. El rastreo de cartas que hace José M. Hernández lo lleva a concluir que Gómez y Maceo estaban en completo acuerdo respecto a Martí: ambos se oponían a la doctrina martiana de un gobierno civil que orquestase la guerra; sin embargo, en tanto que Maceo manifestaba abiertamente sus desacuerdos, Gómez, más diplomático, daba la impresión de aceptar las aspiraciones civiles de Martí (24).

Casi ocho años después de la carta acusatoria que Martí dirigiera a Gómez, y tras los esfuerzos de acercamiento y reconciliacion, iniciados por Martí y secundados por Gómez, encontramos la siguiente descripción de Gómez sobre Martí en una carta dirigida a Serafín Sánchez y fechada el 4 de agosto de 1892:

Martí es todo corazón cubano, en materia de intereses me debe el concepto de que su pureza es inmaculada - puede ir a batirse en los campos de Cuba por la redención de su Patria, con igual denuedo que Luaces y los Agramontes- todo eso es Martí; pero carece de abnegación y es inexorable. No le perdonará a Ud. jamás, lo que él puede clasificar de desdén, y no sea más que desacuerdo, no será nunca capaz de marchar en la misma fila con Ud. creyéndose superior. Por eso para que él mismo no se anule, para que sus rencores no hagan poco eficaces sus valiosos trabajos por la Patria, porque en realidad lo son, es preciso dejarlo hacer: Y nosotros todos, los hombres de armas, los del sacrificio cruento, los tremendos en la guerra, debemos ser, o procurar serlo, los más pacíficos en la paz, y esperar sencillamente, que ellos nos armen y nos despachen para el campo. Sin meternos en averiguar cómo ni cuándo; eso debemos hacer para no perder dos cosas preciosas: la una buena de aprovecharse, el tiempo; la otra, digna de conservarse, nuestro prestigio ( $E l$ general Gómez 167).

Todo lo que sabemos actualmente del carácter de Martí nos compele a negar la posibilidad de que pudiera haber habido en el Apóstol sentimientos innobles como el rencor y la intolerancia de que lo acusa Gómez en esta carta. Hoy día sabemos que Gómez se equivocó al acusar a Martí de falta de abnegación pero, a pesar de la ceguera que pudiera haber impedido que Gómez leyera en sus palabras una proyección de su propio rencor, a pesar de los intereses que pudieran haber motivado su evaluación de Martí: ¿se equivoca también al acusarlo de poseer un rencor capaz de anularlo? Si analizamos la retórica romántica, tan determinante en la formación de Martí, notaremos cómo en ella —en la percepción del mundo que esa retórica delata-el rencor se transforma en beatitud y gloria para el poeta mártir que, como Martí, ha sido modelo de todo cubano.

La facilidad con que en Martí el rencor se confunde con el amor se entenderá mejor si tomamos en cuenta lo muy en boga que estuvo durante el romanticismo el casamiento de esos términos antagónicos. Ya en Abdala (1869), obra juvenil y muy impregnada de romanticismo patriótico, Martí da una explicación de las relaciones entre el amor a la patria y el odio o rencor. En esta definición amor y odio coexisten como si fueran un mismo sentimiento: 
$\mathrm{Ni}$ a la yerba que pisan nuestras plantas;

Es el odio invencible a quien la oprime,

Es el rencor eterno a quien la ataca [...] (Obras Completas XVIII, 19).

De manera similar la correspondencia entre el amor y el temor que había establecido José de la Luz y Caballero, Martí une en estos versos amor y odio. No hay duda que en el caso de Martí, como en el de su admirado maestro, esa percepción de mundo va más allá de los límites del romanticismo y se inserta en el argumento del gran drama escrito y reescrito por Occidente durante todos estos siglos de tradición hebreo-cristiana. También en la crónica que escribe Martí en 1871, "El presidio político en Cuba", religión y romanticismo se unen para producir una visión confusamente maniquea de la realidad. ${ }^{5}$ Veamos cómo en la siguiente cita de esa crónica el rencor — que aparece aquí disfrazado de despreciose reviste de compasión y perdón. Recordemos que en este fragmento Martí apostrofa a los españoles encargados del presidio que él mismo sufrió en su juventud:

Dios existe, y si me hacéis alejar de aquí sin arrancar de vosotros la cobarde, la malaventurada indiferencia, dejadme que os desprecie, ya que yo no puedo odiar a nadie; dejadme que os compadezca en nombre de mi Dios.

$\mathrm{Ni}$ os odiaré ni os maldeciré.

Si yo odiara a alguien, me odiaría por ello a mí mismo (Obras Completas I, 45).

Tal ha sido el legado de esta retórica — sobre todo si se trata de contradecir a Martíque todavía hoy cuesta trabajo admitir que el desprecio y la compasión son sentimientos incompatibles, y que no es posible sentir verdadera compasión por alguien a quien se desprecia. Pero recordemos que la compasión surge de una total identificación y simpatía entre el sujeto y su Otro y que la percepción de diferencias - sobre todo aquellas cargadas de valor moral- no sólo contradice la compasión sino que la anula. Sin embargo, una y otra vez en esta crónica, Martí repite que es incapaz de odiar y que lo único que siente es compasión y desprecio por los "miserables" a quienes, insiste, no puede odiar: "Sois demasiado viles para que os devuelva golpe por golpe y herida por herida. Yo siento en mí a este Dios; yo tengo en mí a este Dios; existe Dios en mí que os tiene lástima, más lástima que horror y que desprecio" (162, subrayado mío).

Cuando Martí glorifica el dolor del patriota mártir se inserta en lo que ya era una respetable tradición de poetas cubanos. ${ }^{6}$ Es posible rastrear las huellas de esa tradición a través de los poemas de un célebre e influyente libro publicado en Nueva York en 1858, El laúd del desterrado. Se trata de una colección de poemas de tema patriótico en la que participan siete exiliados políticos cubanos. En la introducción a la reciente edición crítica del poemario, Matías Montes-Huidobro explica que El laúd del desterrado "juega un primerísimo papel en la formación ideológica nacional y en la trayectoria hacia la

\footnotetext{
${ }^{5}$ Jorge Mañach ha señalado que las dos influencias más visibles en esta crónica de Martí son La Biblia y Víctor Hugo (178).

${ }^{6}$ El discurso de José Manuel Carbonell, "Los poetas cubanos y el ideal de independencia", pronunciado el 21 de mayo de 1927 y publicado dos años después, ofrece una extensa lista de los muchos poetas que trataron el tema.
} 
independencia" (vii). ¿Qué, además de patriotismo y exilio, hay en esos poemas que tanto impacto han tenido en la formación de la conciencia nacional cubana? Si tomamos en cuenta el contenido emotivo que recorre las páginas del libro notamos que, detrás del patriotismo y del destierro, lo que hay es amor y odio. Esto lo confirma la descripción que hizo Enrique Piñeyro de los siete poetas: "No obstante las diferencias individuales del carácter y el grado del talento, tienen un rasgo común, un lazo que los llena y arrebata: amor ardiente de la libertad de la patria, odio irreconciliable a la dominación española" (22, subrayado mio).

Uno de los móviles que caracteriza la mayor parte de los poemas de ese libro es el deseo de dar testimonio de las injusticias que España comete en Cuba. El poemario comienza con el célebre "Himno del desterrado" de José María Heredia. El yo lírico aquí se presenta como afortunado mártir ya que otros, los que quedan en Cuba, envidiarán su martirio: "Aún habrá corazones en Cuba/ que me envidien de mártir la suerte" (8). La presentación del poeta como mártir no sólo aparece en el primer poema de este libro sino que — desde la primera edición de las poesías de Heredia en 1825 - inaugura toda una tradición poética. Otro rasgo que formará parte de esta tradición y que también vemos en este poema es el de las relaciones triangulares entre Cuba/madre, el español/padre, y el poeta/hijo. El romance familiar explica la confusión de sentimientos que caracterizan el célebre triángulo: amor, odio, culpa. En el "Himno del desterrado", el papel de Cuba como madre amada queda claro en los célebres versos: "Cuba, Cuba, que vida me diste,/ dulce tierra de luz y hermosura,/ ¡cuánto sueño de gloria y ventura/ tengo unido a tu suelo feliz!" (7). Más adelante vemos el odio hacia el padre "déspota". Sin embargo, los sentimientos no siempre fluyen en esa clara dirección: amor hacia Cuba, odio e imputación de culpas hacia los españoles. Se da también el caso de que el amor hacia Cuba aparece contaminado de reproches. Por ejemplo, en los siguientes versos hay una acusación implícita de la culpa de la madre/Cuba que, en su ignorancia, no sólo adora al padre "déspota" sino —en él—al demonio mismo: "Te hizo el cielo la flor de la tierra,/ mas tu fuerza y destinos ignoras,/ y de España en el déspota adoras/ al demonio sangriento del mal" (8). Siguiendo la lectura del romance familiar, con todas sus implicaciones freudianas, vemos que esa "femenina" ignorancia de la madre/Cuba será rectificada por el poeta, quien no sólo está dispuesto a esgrimir su pluma para reeducar y llevar a Cuba por el camino del "buen amor", sino que está dispuesto a esgrimir la espada parricida a fin de conseguirlo.

Ya que ésta es sólo una entre muchas lecturas posibles, no se hace necesario explorar a fondo la interpretación del poema a la luz de la dinámica del romance familiar. Pero sí es bueno ver, otra vez, la confluencia de sentimientos contrarios —amor y rencor- y la manera en que esa confluencia está asociada al motivo de la culpa. Está claro que las huellas de la retórica de la culpa hay que buscarlas en las raíces mismas de la cultura, sobre todo en su herencia religiosa; sin embargo, la poesía patriótica del siglo diecinueve representa, para Cuba, un hito importante en esa antiquísima trayectoria. Los ejemplos son incontables. Acabamos de ver uno en ese inaugural poema que fue el "Himno del desterrado". Como en el poema de Heredia, hay muchos otros en los que no sólo se acusa a España sino a los cubanos que no se alzaron para combatir al enemigo. Ese es el caso de otro de los poemas del libro, "Canto de un desterrado", de Miguel T. Tolón: "Que de eterna vergüenza se cubra/ quien no empuñe la espada o la lanza, pero el héroe que laudos alcanza/ ‘ $i V i v a ~ C u b a ! '$ aun muriendo dirá" (50). 
No hay duda de que los poemas de El laúd del desterrado ejemplifican lo que hoy día llamamos arte comprometido. Como suele ocurrir con ese tipo de literatura, el compromiso conduce al testimonio, y en específico al de las culpas cometidas por los enemigos de la patria. Posiblemente el poeta cubano del diecinueve que mejor dramatiza las consecuencias extremas a que llevan las imputaciones de culpas fue Juan Clemente Zenea (1832-1871). Ya que la figura de Zenea dejó su marca importante en la historia del diecinueve cubano, será bueno tomar en cuenta la relación entre su visión de mundo, típicamente romántica, y su destino. Algo notable en este poeta es el hecho de que sus actividades patrióticas no lo limitaron a servir la causa de la independencia con su pluma - como fue el caso con los poemas suyos que aparecieron de El laúd del desterrado. Ya en 1852 su labor propagandística lo llevó a un exilio que se hizo más imperativo cuando al año siguiente un tribunal habanero lo condenó a muerte. En 1869, durante la primera guerra de independencia, participó en una fallida expedición militar. Poco después, en 1870, cuando creyó que lo mejor para Cuba sería ponerle fin a esa guerra, viajó otra vez a Cuba en una misión diplomática cuyo propósito era la búsqueda de un final pacífico para la guerra del 68. Por desgracia el salvoconducto con que viajaba lo hizo parecer culpable ante los españoles y ante los cubanos rebeldes, y esto causó que fuera doblemente acusado de traidor - por España y por los cubanos en armas - y que muriera fusilado a los treinta y nueve años de edad.

Poco antes de morir Zenea escribió una colección de dieciséis poemas que, apenas unos meses después de su ejecución, los editores neoyorquinos de Mundo Nuevo publicaron bajo el título de Diario de un mártir (1871). Aunque no aparece en El laúd del desterrado, su poema patriótico más célebre es sin duda "En días de esclavitud". Se trata de un poema extenso, dividido en cuatro partes, cuyo alto contenido emotivo fluctúa entre una tristeza llena de lirismo y nostalgia, y ese rencor patriótico que ya hemos visto en otros poemas de la época. La primera parte comienza con la tristeza asociada al destierro del poeta que se aleja, por mar, de la tierra esclava. La tristeza se vuelve desolación en la parte dos, donde encontramos estrofas que coinciden con los cuestionamientos existenciales del poeta enajenado de su mundo y del tiempo en que le tocó nacer: "La estrella de mi siglo se ha eclipsado,/ y en medio del dolor y el desconsuelo/ el lirio de la fe se ha marchitado y no hay escala que conduzca al cielo" (94).

En la parte tres, el poeta se embarca en un imaginario viaje hacia el origen. Su recorrido empieza de manera personal, aludiendo al amor a la libertad que ya sentía desde la infancia y la adolescencia. Consistente con su evocación del tiempo perdido, el yo lírico abandona entonces lo personal y se concentra en los orígenes de la patria. Hay aquí una recreación de la llegada de los españoles al Nuevo Mundo en la que el tema de la culpa se desarrolla por medio de una especulación sobre los males que se habrían podido evitar si la llegada de los españoles nunca hubiera ocurrido:

No el peso del ominoso yugo de infausta servidumbre

sufrido hubieran inocentes seres; $y$ el indio humilde con su tez de cobre, y el blanco abyecto con su faz de rosa. Y el hijo del dolor, el negro pobre, y mártires mujeres, 
y niños ¡ay!, que asesinó el verdugo, ninguno entonces contemplado hubiera la suerte ignominiosa, ¡de aquella desgraciada muchedumbre que pasto fue de la indomable fiera! (98).

La cuarta y última parte comienza con la sordera del mundo que no escucha los gritos de dolor de todo un pueblo y de repente, en la última estrofa, hay una imagen bélica que se resuelve en la visión profética que anuncia un final feliz. A pesar del profundo sentimiento de dolor que recorre todo el poema, éste concluye con la promesa de redención que llegará cuando la bandera de la estrella solitaria ondee victoriosa en la batalla final: "iy en medio de los himnos de la guerra/ al fin el pueblo vencedor saluda/ el pendón de la estrella solitaria!" (102).

Si esa profecía de triunfo era la espuela que impulsaba a Zenea y a tantos de sus compatriotas, ¿por qué en el 98 no se llega a cumplir de la manera limpia y tajante que tanto patriota cubano, incluyendo a Martí, ambicionó para Cuba? Una respuesta a esta pregunta la encontramos en el legado de la visión de mundo que el romanticismo exaltó y que se caracteriza por la fluctuación entre dos maneras de percibir el mundo, íntimamente ligadas entre sí. Por un lado está el siempre manifesto pero con frecuencia frustrado deseo de unir a los contrarios, para de esa manera lograr el ideal de libertad y amor. Por el otro lado está el testimonio del sujeto prisionero de una percepción que ya no le muestra puentes ni correspondencias sino fragmentación, aislamiento, temor y culpas. Es cierto que son muchos los factores que determinaron los eventos que culminaron en el 98. Entre ellos, uno importante fue el papel que jugó el legado romántico que sustentaba la ideología de la época. Un ejemplo aun más claro de esa visión de mundo nos lo ofrece la siguiente auto-descripción de Zenea:

El tiempo se ha llevado consigo gran parte de mi energía, pero a más de los daños que me ha ocasionado este enemigo, yo me he devorado a mí mismo, porque me he entregado en los brazos de las furias que se llaman las pasiones. He ido dejando aquí y allí pedazos del corazón [...] he recorrido algunos pueblos, me he asociado a todos los grandes pensamientos, al cabo me he convencido como Werther de la especial uniformidad del género humano; conozco, por último, que yo sería más feliz si no me hubiese arrojado en la corriente impetuosa del mundo, y que la experiencia ha llegado para mí, más que por la vía de los años, por la vía espinosa del afán, del estudio, de las conmociones, del amor, de la pena (En Piñeyro 59-60).

En tanto que en "En días de esclavitud" la "indomable fiera" era el español culpable de las atrocidades hacia el "indio humilde", el criollo "blanco abyecto", el "negro pobre", las "mártires mujeres" y los niños, en el fragmento anterior el enemigo se ha internalizado. Zenea admite la existencia de un enemigo en quien reconocemos la manifestación interna de la culpa/"furias". ¿Qué culpa o "fiera indomable" es ésta que unas veces devora por dentro y otras se exterioriza? Si se tratase del "pecado original" mencionado por Luz y Caballero, es decir, la esclavitud del negro por el blanco, incluyendo al "blanco abyecto" nacido en Cuba, tendremos que admitir que el poema de Zenea apenas si alude a ese pecado. 
Y aquí la casi omisión del "pecado original" hace aún más conspicua su presencia. Siguiéndole la pista a esa omisión, consideremos ahora el siguiente comentario de Cintio Vitier sobre "En días de esclavitud", poema éste que, según Vitier, representa la culminación del romanticismo cubano:

Nuestro romanticismo, culminante en Zenea, coincide a través de dos generaciones con la toma de conciencia de la patria esclavizada y del "pecado original" (según la sentencia de José de la Luz) que sustentaba y deformaba a la sociedad cubana, encarnó y expresó esa situación histórica, políticay social, en todos los planos: desde la indignada renuncia ética y patriótica, pasando por las búsquedas de una identidad costumbrista y vernácula (incluso, fallidamente, indigenista), hasta los niveles más hondos e irradiantes de la intimidad y la trascendencia. Ningún poema fue tan capaz de recoger estos últimos registros, sin perder nunca de vista la estrella revolucionaria que los imantaba, como el titulado "En días de esclavitud", verdadera summa del más acendrado y militante romanticismo cubano (706).

En ese párrafo Vitier le habla a un lector que conoce la obra de José de la Luz y Caballero y recuerda que para el pensador y maestro de Zenea, el pecado original de Cuba era la esclavitud. Presumimos que es la obligación de ese lector informado notar de qué manera la esclavitud de los negros en Cuba trabaja implícitamente como alusión importante en el poema de Zenea. Pero Vitier en ningún momento se detiene a desarrollar esa válida idea. Y es que Zenea apenas si menciona al "negro pobre", y cuando lo hace, lo incluye en mitad de una lista de víctimas de la "indomable fiera": el español que en este poema aparece como el único culpable de la esclavitud. Esa inclusión del "negro pobre" como una entre muchas víctimas, más que dar testimonio de las injusticias de la esclavitud negra lo que hace es restarle importancia. Sabemos que la patria esclavizada de Zenea le debe mucho su esclavitud económica y política a esa otra esclavitud o pecado original que sufrió la población negra. Sin embargo, en el célebre poema de Zenea lo que Vitier califica como "la toma de conciencia del 'pecado original' [...] que sustentaba y deformaba a la sociedad cubana" no pasa de ser una proyección de culpas dirigida a España. Lo cierto es que una culpa no declarada ni confrontada por Zenea en este poema que Vitier consigna como la culminación del romanticismo cubano, la culpa apenas admitida por el propio Vitier, es la que siente el cubano blanco que sabe que la esclavitud del país le debe mucho a la esclavitud racial.

No es necesario detenernos a considerar cómo la esclavitud fue causante de incontables conflictos entre los diferentes partidos e intereses que abogaban por la libertad de Cuba. Baste recordar que los miedos asociados a la esclavitud de negros en Cuba demoraron y en ocasiones coartaron los esfuerzos hacia la independencia, y que la fragmentación que ese "pecado original" causó entre los cubanos del diecinueve fue motivo de rencillas e intrigas entre los líderes de la independencia. ${ }^{7}$ Sin embargo, la esclavitud no fue la única causa que

\footnotetext{
${ }^{7}$ Aunque el problema fue mayor durante la guerra de Yara, la semilla de la intriga y la desconfianza ya había sido sembrada y siguió germinando entre los diferentes grupos que lucharon por la independencia en la guerra del 95 . "The truth is that, from the standpoint of civil-military relations, Cubans were in 1898 in exactly the same situation that they had been at the end of the Ten Year's War. As the struggle had dragged on, the civilian leadership had waned and the military chieftains had gained the upper hand" (Hernández 48).
} 
motivó la fragmentación entre los diversos grupos que luchaban en esas guerras. Hoy día sabemos que la manzana de la discordia socavó muchos de los esfuerzos de estos grupos, dentro y fuera de la isla. ${ }^{8}$ Lo cierto es que, aunque todavía cueste aceptarlo, el país al que llegaron las tropas norteamericanas a raíz de la explosión del Maine había sido devorado por una "fiera indomable" que no sólo agredía para defender el pendón español, sino que en ocasiones se devoraba y anulaba internamente.

Ha sido difícil llegar a una definición tangible de lo que representó para Cuba el 1898 porque ese año no marca con precisión ni derrota ni victoria sino, entre otras cosas, la prórroga de la identidad nacional. Si es cierto que la historia es un entretejer de textos que dialogan entre sí, importa entonces notar la relación intertextual entre los eventos del 98 y la honda fragmentación de la identidad que caracteriza la poesía romántica de tema patriótico que, como ya hemos visto, fue tan influyente en la adquisición de la identidad nacional. Una gran parte de esa poesía no sólo presenta una identidad nacional fragmentada sino que intenta distinguir - no siempre con éxito- entre las jerarquías morales de los fragmentos: héroes y cobardes, desterrados y habitantes de la isla, inocentes y culpables. La existencia de una serie de textos en los que la fragmentación se internaliza es significativa a la hora de dar con esa culpa detrás de las culpas. Ya que Martí fue uno de los primeros en recibir y diseminar ese legado del romanticismo, veamos cómo dos de sus poemas de Las flores del destierro ilustran la fragmentación interna. La siguiente estrofa de "Dentro de mí" alude a la fiera interior: "Dentro de mí hay un león enfrenado:/ De mi corazón he labrado sus riendas:/ Tú me lo rompiste: cuando lo vi roto/ Me pareció bien enfrenar la fiera" (XVI, 271). Si notamos que este poema pone de manifiesto la fragmentación del sujeto, podemos afirmar que el "tú" al que apostrofa el hablante es menos la amada que una proyección de su propio "yo" fragmentado. La fiera es, a su vez la manifestación del rencor y la culpa que produce la fragmentación. Y aquí debemos recordar aquella frase de la crónica, "El presidio político en Cuba", en la que el joven Martí advertía: "Si yo odiara a alguien, me odiaría por ello a mí mismo" (Obras Completas I, 45). Otra alusión a la fiera interna la vemos en, "Señor: en vano intento":

Señor: en vano intento

Contener el león que me devora ...

¡Señor, Señor! yo siento

Que esta alta torre se derrumba al viento.

A la pasión, al tigre que me muerde

El poder de embridar el alma pierde.

¡Señor, Señor! no quieras

Mi pobre corazón dar a las fieras (XVI, 281).

Estos poemas de Martí nos dejan ver lo muy cerca que está ese "yo" fragmentado del "yo me he devorado a mí mismo" con que Zenea describiera sus furias. Y es que el legado

\footnotetext{
${ }^{8}$ Un ejemplo de las divisiones que plagaban laépoca lo ofrece las intrigas alrededor del encarcelamiento y muerte del propio Zenea. La justificación de su inocencia, ha motivado la labor apologética de críticos como Piñeyro y Vitier.
} 
romántico - que tanto influyera en Martí - lo hace fluctuar entre dos visiones de mundo que tienen mucho que ver con el tipo de símbolos que usa en su obra; símbolos éstos que, como advierte Iván Schulman, reflejan unas veces una filosofía dualista —en la que las polaridades se mantienen irreconciliadas- en tanto que en otras la polaridad se resuelve, o en trascendencia o en síntesis (Schulman 82).

Ya que la ideología martiana ha tenido y sigue teniendo un profundo impacto en nuestra visión de mundo, importa tener en cuenta que ni Martí ni el modernismo lograron superar las fluctuaciones que caracterizaron las obras de los escritores románticos. Es cierto que detrás del empeño del poeta romántico por alzar puentes para reconciliar a los contrarios hay un fuerte sentimiento de libertad, y también un deseo de derrumbar los obstáculos que encarcelan al "yo" dividido, enajenado, separado de sí mismo y de cuanto le rodea. Sin embargo, el acto de percibir la separación y dar testimonio crítico de ella es, inevitablemente, otra manera de perpetuarla. Cuando la percepción del abismo entre sujeto y mundo se hace más lúcida $-\mathrm{y}$ este es el caso de los poetas y pensadores críticos del siglo diecinueve cubano- el impulso por derrumbar obstáculos muchas veces se contamina de un deseo de proteger la caída en lo desconocido. El sujeto amenazado por su percepción de sí como isla en un océano de diferencias, transforma los puentes en murallas que lo protejan en su vulnerabilidad.

La historia literaria ha asociado en Hispanoamérica el espíritu de libertad romántico con las guerras de independencia. No debe entonces sorprendernos que ese deseo de unión y libertad, representado por el mítico "sueño de Bolívar", haya desembocado en guerras civiles, fragmentación política y proliferación de gobiernos autoritarios. No debe sorprendernos tampoco que, a pesar de las críticas advertencias de Martí, también los héroes de la independencia cubana estuvieran divididos en sus aspiraciones para Cuba y que, a pesar de los ejemplos de caudillismo que ya había dado la Hispanoamérica "independiente", también la mayoría de ellos estuviera inclinada en esa dirección (Hernández 8-11, 23-25, 48). Las huellas del caudillismo hispanoamericano se han trazado a las invasiones que durante siglos sufrieron los habitantes de la península ibérica y al espíritu individualista, tribal, que esas invasiones instigaron en quienes serían los futuros conquistadores de América (Chang-Rodríguez 82). Sin restarle mérito ni veracidad a esa lectura, hoy día sabemos que el problema es más universal e inmediato. Somos los Segismundos de las mazmorras del lenguaje, de la percepción enajenada que el lenguaje nos devuelve de nosotros mismos. Nuestras únicas libertades son: o bien el vivir la pesadilla sin distanciarnos de ella, es decir, sin cuestionarla, o tratar todo el tiempo de no olvidar — para de esa manera evitar las innecesarias imputaciones de culpas-el hecho de que cada palabra que emitimos equivale a un ladrillo que colocamos en el puente o la muralla soñados.

Bibliografía

Benítez-Rojo, Manuel. La isla que se repite. El Caribe y la perspectiva moderna. Hanover: Ediciones del Norte, 1989.

Bush, Andrew. "Lyric Poetry of the Eighteenth and Nineteenth Centuries". The Cambridge History of Latin American Literature. Roberto González Echevarría y Enrique PupoWalker, eds. Cambridge: Cambridge University Press, 1996. 
Carbonell, José Manuel. Los poetas cubanos y el ideal de independencia. Habana: Avisador Comercial, 1929.

Chang-Rodríguez, Eugenio. Latinoamérica, su civilización y su cultura. 2da edición. Massachusetts: Heinle \& Heinle, 1991.

Hernández, José M. Cuba and the United States. Intervention and Militarism, 1868-1933. Austin: The University of Texas Press, 1993.

Luzy Caballero, José de la. Aforismos de Luz y Caballero. La Habana: Editorial Lex, 1960. Lyotard, Jean-Françoise. The Postmodern Condition: A Report on Knowledge. Geoff Bennington y Brian Massumi, trads. Minneapolis: University of Minnesota Press, 1989.

Martí, José. Obras completas. La Habana: Editorial Nacional de Cuba, 1964. El general Gómez. La Habana: Centro de Estudios Martianos, 1986.

Mañach, Jorge. Historia y estilo. Edición Facsimilar. Prólogo Rosario Rexach. Miami: Editorial Cubana, 1994.

Montes-Huidobro, Matías. El laúd del desterrado. Texas: Arte Público Press, 1995.

Moreno Fraginals, Manuel. Cuba/España, España/Cuba. Historia común. Barcelona: Grijalbo Mondadori, 1995.

Pérez Guzmán, Francisco. "La revolución del 95. Desde la conclusión de la Campaña de Invasión hasta el fin de la dominación española". Tomo 2. Historia de Cuba. Las luchas por la independencia nacional y las transformaciones estructurales. 18681898. La Habana: Editora Política, 1996. 481-543.

Pérez, Louis A. Cuba. Between Reform and Revolution. 2da ed. Oxford: Oxford University Press, 1995.

Piñeyro, Enrique. Vida y escritos de Juan Clemente Zenea. La Habana: Consejo Nacional de Cultura, 1964.

Schulman, Iván. Símbolo y color en la obra de José Martí. Madrid: Gredos, 1960.

Vitier, Cintio. "Zenea y el romanticismo cubano". Revista Iberoamericana 56(1990): 703713.

Vitier, Medardo. Las ideas en Cuba. 2 tomos. La Habana: Editorial Trópico, 1938.

Zenea, Juan Clemente. Diario de un mártiry otros poemas. Angel Aparicio Laurencio, ed.

Miami: Ediciones Universal, 1972. 